Abstracta Iranica Abstracta Iranica

Revue bibliographique pour le domaine irano-aryen

Volume 23 | 2002

Comptes rendus des publications de $\mathbf{2 0 0 0}$

\title{
Histoire de l'islam. Fondements et doctrines. Paris, Flammarion, 2000, 311 p. (Champs Université), glossaire, biblio. et index.
}

\section{Denise Aigle}

\section{(2) OpenEdition}

Journals

Édition électronique

URL : http://journals.openedition.org/abstractairanica/35515

DOI : 10.4000/abstractairanica.35515

ISSN : 1961-960X

Éditeur :

CNRS (UMR 7528 Mondes iraniens et indiens), Éditions de l'IFRI

Édition imprimée

Date de publication : 15 mai 2002

ISSN : 0240-8910

Référence électronique

Denise Aigle, "Histoire de l'islam. Fondements et doctrines. Paris, Flammarion, 2000, 311 p. (Champs Université), glossaire, biblio. et index. », Abstracta Iranica [En ligne], Volume $23 \mid 2002$, document 202, mis en ligne le 08 février 2010, consulté le 25 septembre 2020. URL : http://journals.openedition.org/ abstractairanica/35515; DOI : https://doi.org/10.4000/abstractairanica.35515

Ce document a été généré automatiquement le 25 septembre 2020.

Tous droits réservés 


\title{
Histoire de l'islam. Fondements et doctrines. Paris, Flammarion, 2000, 311 p. (Champs Université), glossaire, biblio. et index.
}

\author{
Denise Aigle
}

1 Ce livre est un manuel à l'usage des étudiants des universités publié chez Flammarion dans la nouvelle collection "Champs Université ». Son objectif est de présenter une histoire des développements doctrinaux de l'islam ou plutôt, comme le souligne son auteur, «des islams et des pluralismes dans l'islam ». L'histoire de l'islam, depuis ses débuts jusqu'à l'époque contemporaine, est abordée en dix chapitres.

2 Le chapitre I «De la jâhiliyya à l'islam » (pp.11-29) décrit l'évolution du hanîfisme ambiant vers l'islam et comment s'est formée la communauté islamique par un passage de la confédération tribale à un Etat. Le chapitre II « Le Coran» (pp. 30-47) explique la manière dont on est arrivé à la science de l'exégèse (tafsir). Le chapitre III « Le Prophète comme modèle : la sunna et la sira » (pp. 48-63) traite de l'instauration du " sunnisme », à travers la constitution du corpus des hadīt-s, la collecte des récits sur sa vie (sīra). La sunna du Prophète est présentée comme un «proto-sunnisme ». Le chapitre IV "Le droit islamique et sa méthodologie » (pp. 64-81) s'attache à retracer les origines du figh, l'histoire des différentes écoles ainsi que leurs méthodes et techniques propres. Le chapitre V «L'élaboration de la théologie » (pp. 82-98) retrace la formation des écoles théologiques et montre comment, face au mutazilisme, la solution ach'arite a finalement défini une "orthodoxie sunnite». Le chapitre VI "Les schismes dans l'islam» (pp. 99-121) expose de manière claire la distinction qu'il convient d'établir entre les Kharijites, les Ibadites et les différents mouvements chiites (zaydisme, ismaélisme, gulāt). Le chapitre VII «Le chiisme duodécimain » (pp. 122-138) définit ses spécificités théologique et retrace les développements de sa méthode juridique, laquelle a conduit à l'instauration de la marjaciyya puis à la " guidance du juriste». Le chapitre VIII "Théories et pratiques du soufisme» (pp.139-151) est un survol du 
développement des mouvements mystique de l'islam, des premiers ascètes à l'expansion des ordres. Le chapitre IX «Les réformismes, entre réaction et modernisme » (pp. 152-168) montre que, dans l'islam, il a existé un réformisme avant la réforme. L'exemple en la matière est l'œuvre monumentale de Abū Ḥamīd al-Ġazzālī, le Ihyā 'ulūm al-dīn (La revivification des sciences religieuses), dans lequel il tentait de concilier les prescriptions du figh et le soufisme. Le chapitre $\mathrm{X}$ « Les courants de pensée dans l'islam contemporain" (pp.169-181) explique les fondements sur lesquels s'appuient aujourd'hui les mouvements islamistes, le socle doctrinal en étant le réformisme et la salafiyya.

3 Ce petit livre sera d'une très grande utilité, non seulement par le contenu des dix chapitres, rédigés de manière claire, mais aussi par la manière très pédagogique dont $\mathrm{il}$ est conçu. Les dix chapitres sont en effet accompagnés d'un glossaire critique des «mots et thèmes", des «acteurs et institutions» et des «lieux» (pp. 199-270), présenté sous la forme de courtes notices, complétées par une bibliographie succincte destinée au lecteur qui désire en savoir plus sur le sujet. Une chronologie des principaux événements (pp.271-278), une bibliographie, présentée de manière systématique : instruments de travail (encyclopédies et revues), ouvrages généraux et bibliographie par chapitre (pp. 277-291), un index des noms (pp. 293-299) et des notions (pp. 301-308) complètent l'ouvrage. Il est dommage que l'Encyclopaedia Iranica et les revues bibliographiques françaises (Bulletin critique des Annales islamologiques et Abstracta Iranica) aient été oubliées.

\section{INDEX}

Thèmes : 7. Islam

\section{AUTEURS}

DENISE AIGLE

IFEAD - Damas 